\title{
THE INFLUENCE OF FERRO-SILICON ADDITION ON THE REDUCTION AND SULFURIZATION OF Co, Cu AND Ge- BEARING SMELTER SLAG WITH CARBON AND CALCIUM SULFATE
}

\author{
Junior Ngoyi KAYEMBE, Michel Kalenga WA KALENGA, Didier Kasongo NYEMBWE \\ University of Johannesburg, Department of metallurgy, School of Mining Metallurgy and Chemical \\ Engineering Faculty of Engineering and the Built Environment South Africa \\ jukvert@gmail.com, dnyembwe@uj.ac.za, michelk@uj.ac.za
}

https://doi.org/10.37904/metal.2021.4245

\begin{abstract}
The current appetite for base metals, primary metals resources are being depleted; theneed to recycling waste of primary metallurgy such as slag is on the rise. This study investigates the recovery of $\mathrm{Ge}, \mathrm{Cu}$ and Co with ferrosilicon addition from Ge-copper bearing slag from STL/Gecamines in the Democratic Republic of Congo during carbothermic reduction and sulfurization. Characterization was conducted using XRF, XRD and SEMEDS while a bench scale alumina tube furnace was used for the experiments. Coke was used as reductant while calcium sulfate ( $\mathrm{CaSO}_{4}$-high purity) was added for sulfurization. Graphite crucibles were used for the experiments and the furnace set for $1400{ }^{\circ} \mathrm{C}$ using Eurotherm temperature controller. To limit the interaction between the graphite crucible and the slag, $\mathrm{CO}$ was blown in at $0.01 \mathrm{l} / \mathrm{min}$. Products were characterized using XRD coupled with Origin 8.5 software and SEM-EDS. Results have revealed that $\mathrm{Cu}, \mathrm{Co}$ and $\mathrm{Ge}$ were displaced to a matte phase. However, the displacement of $\mathrm{Ge}$ from the silicates matrix to the metallic phase was observed. The formation of $\mathrm{CuGeFe}, \mathrm{CoFe}, \mathrm{CuS}, \mathrm{FeS}$ and some $\mathrm{Cu}$ were present in the metallic phase when $\mathrm{FeSi}$ increased in presence of $\mathrm{CaSO}_{4}$ whereas more amorphous slag was produced due to high silica content.
\end{abstract}

Keywords: Metallurgy, copper slag, reduction, sulfurization, calcium sulfate

\section{INTRODUCTION}

Slags produced in pyrometallurgical processes are promising sources of metals. A huge amount of it is generated each year worldwide $[1,2]$. The generated copper slag contains valuable metals due to mechanical entrapment of fine and dispersed matte or/and due to their dissolution in slag as oxides chemically bound with silica in fayalite as lattice substituents such as germanium [3-7]. Therefore, copper slag can be considered as a secondary source for metals recovery [8].

Different studies have been conducted on recovery of valued metals from copper slag using different approaches [9]. However, the approach chosen on the composition, present form of targeted precious metals and economics involved. Hence, pyrometallurgy has been the most used approach for reduction and sulfurization of metal oxides contained in the slag because of other techniques limitations [7]

Germanium is less abundant in the Earth's crust with an occurrence ranging between 1-7 ppm. It occurs associated with many elements forming known minerals of Germanite and renierite and Ge oxide [10]. Germanium use is mostly the manufacture of semiconductors. New applications in novel and high demand technological industrial have improved its price. This has lead process materials with low germanium contents and significant amounts of other values [11].

Previous studies have exposed diverse secondary sources of germanium but to our knowledge, the recovery of germanium in oxide phase from copper slag has not been done [7,12-15]. 
Previous study has proposed a carbothermal reduction of germanium oxides [15] while another investigation have shown that the reduction need a high temperature with a very high risk of producing germanium monoxide vapor [16]. Hence, the current study investigated the carbothermal reduction of germanium bearing copper slag with the addition of ferro-silicon for germanium dioxide reduction and germanium displacement to the matte.

\subsection{Thermochemistry prediction}

Ferrosilicon is added to support the reduction of germanium dioxide. The Ellingham diagram below has been generated using HSC 9 chemistry software by considering possible reactions between germanium dioxide and some added agents up to $1400^{\circ} \mathrm{C}$.

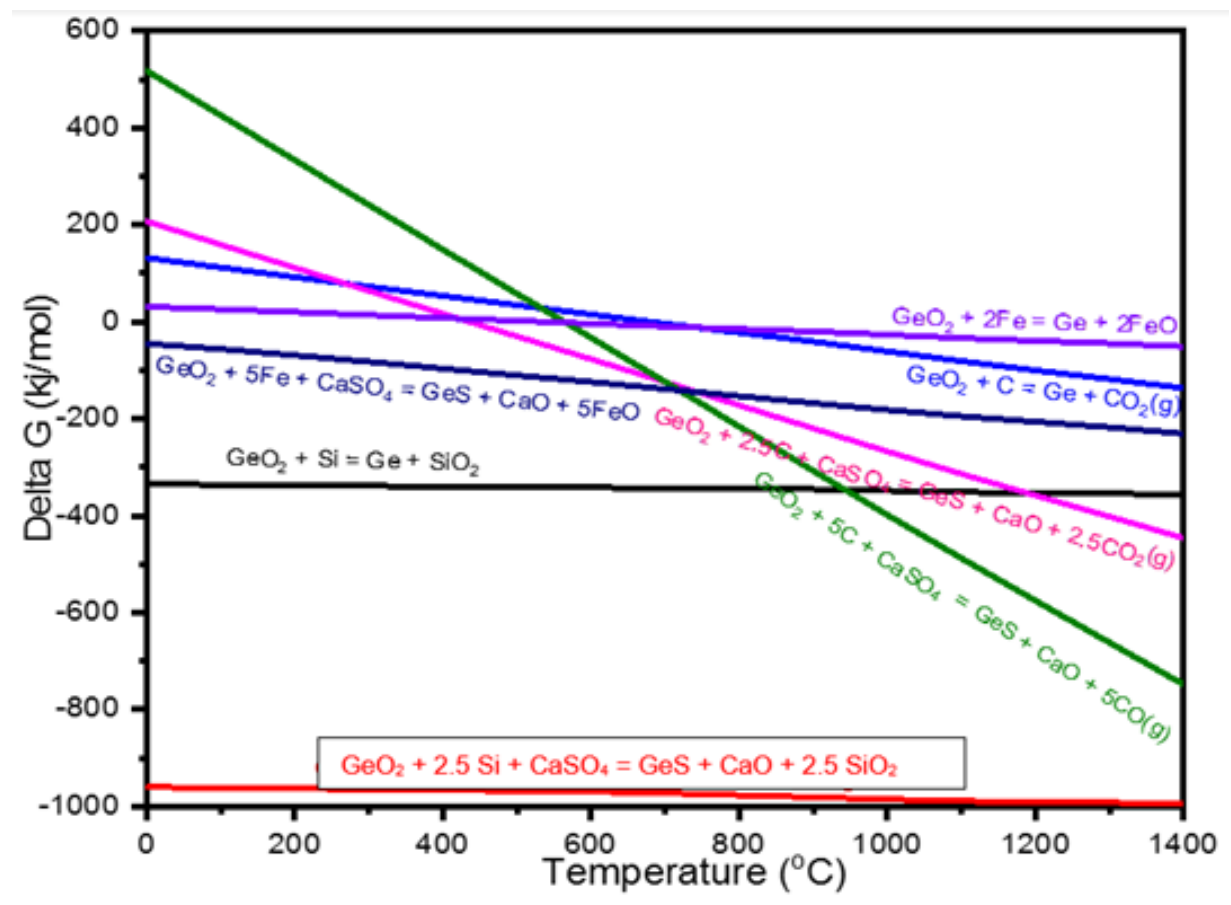

Figure 1 Reduction and sulfurization of $\mathrm{GeO}_{2}$ (Drawn using HSC 9)

The reactions show that germanium dioxide can be reduced at different rate with silicon and iron from ferrosilicon and the reducing agent carbon. Silicon is the strongest reductant due the lowest energy needed to form germanium or even germanium sulfide in sulfurization at $1400{ }^{\circ} \mathrm{C}$. Germanium dioxide will be reduced by carbon, but this process needs higher energy to produce $\mathrm{Ge}$ and $\mathrm{CO}$ even very higher energy to produce $\mathrm{CO}_{2}$ at $1400^{\circ} \mathrm{C}$ in both reduction and sulfurization steps when compared to the reactions with silicon. the reactions germanium dioxide with Iron from ferro-silicon is the least to occur in the system. The Gibbs energies are too high or very close to positive values. Reactions (1) to (8) illustrate.

Gibbs free energies at $1400{ }^{\circ} \mathrm{C}$ indicate that the formation of germanium sulfide is more feasible using silicothermic process in presence of calcium sulphate. The reaction leads to the formation of germanium sulfide that reports to the metallic phase accompanied by the formation of $\mathrm{CaO}$ and $\mathrm{SiO}_{2}$ which report to the slag. However, it transpired that adding carbon as reducing agent in absence of silicon also enhances the formation of germanium sulfide but required a bit more energy than the silicothermic process. It must be noted that the carbothermic process, although easily feasible than the reduction of $\mathrm{GeO} 2$ by iron, it remains less recommendable than the silico thermic process doubled with the addition of calcium sulphate. This is explained by the higher energy required by the carbothermic reduction. However, the amount of carbon needed is higher than where carbon monoxide is produced leading to the reaction producing $\mathrm{GeS}$ and $\mathrm{CO}_{2}$. Finally, the reduction 
and sulfurization of germanium dioxide is very difficult where iron becomes the reductant. This order is followed whether metallic germanium or germanium sulfides are obtained. Therefore, iron from ferro-silicon will only play the role of collecting the reduced germanium and will both sulfurize to the matte with $\mathrm{SO}_{2}$ from $\mathrm{CaSO}_{4}$.

Chemical reactions of $\mathrm{GeO}_{2}$ and Gibbs free energy

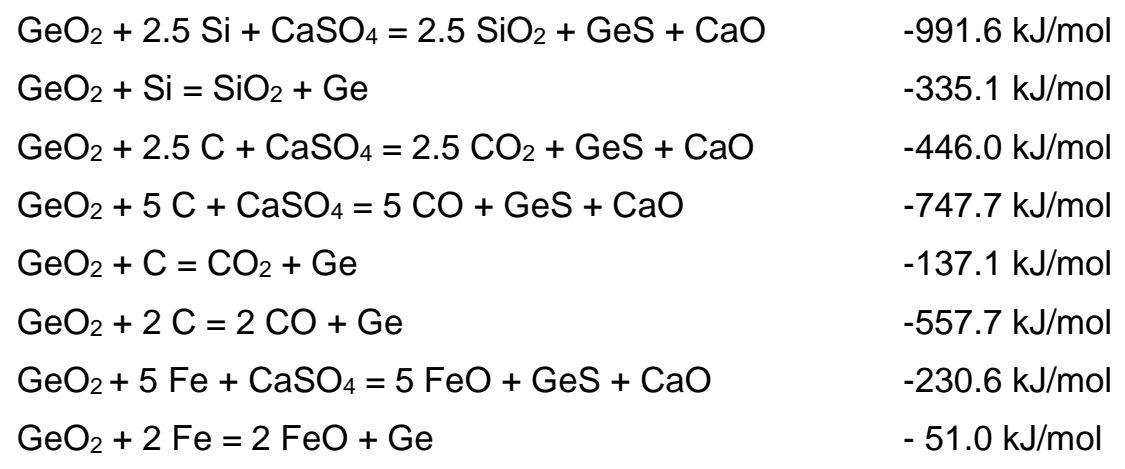

However, the sulfurization dependent on the amount of $\mathrm{SO}_{2}$ in the system as shown in the Figure 2 bellow.

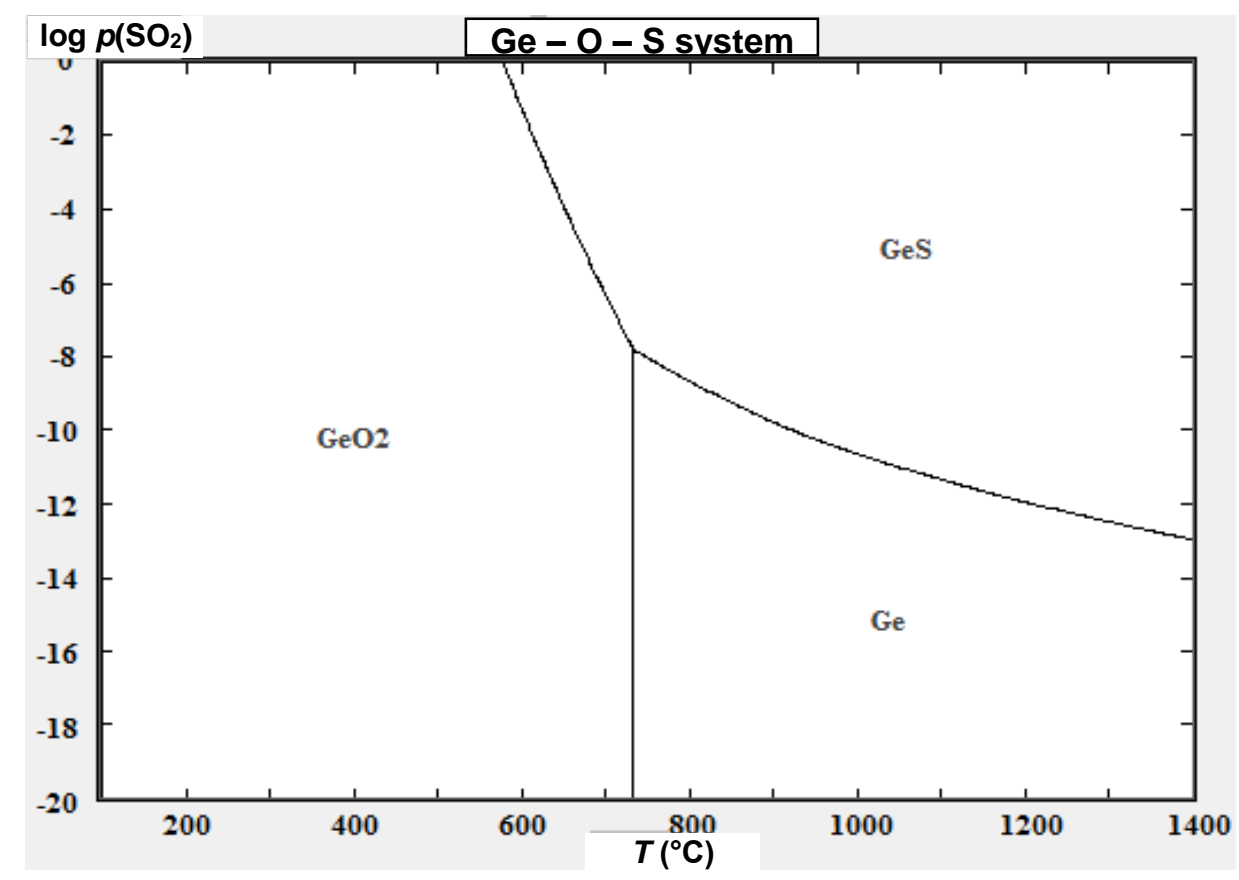

Figure 2 Calculated Ge-O-S system using HSC 9 chemistry software

The decomposition of germanium dioxide to germanium occurs at around $750{ }^{\circ} \mathrm{C}$ when the $\log p \mathrm{SO}_{2}$ is maximum around -8 whereas it gets sulfurized at temperature starting at minimum $750^{\circ} \mathrm{C}$ in presence of $\mathrm{SO}_{2}$. The formation of germanium sulfides occurs at around $600{ }^{\circ} \mathrm{C}$ in the presence of high $\mathrm{SO}_{2}$. This rises the expectation of forming germanium sulfide in a medium where sulfur would be available to react. Therefore, $\mathrm{GeS}$ is expected to report to the matte. However, $\mathrm{SO}_{2}$ content will remain constant because it comes $\mathrm{CaSO}_{4}$ which was added to keep constant the basicity at 0.7 . This is also supported by the fact that primarily the vessel being open on top $\mathrm{SO}_{2}$ my easily escape because its residence time is low. Also, the presence of other metal oxides in the raw slag besides copper oxides and iron oxides may react to form sulfides before germanium dioxide and start consuming $\mathrm{SO}_{2}$. Overall, the Gibbs free energy change of different reactions support the sequence of reactions based on their level of energy requirements. 


\section{METHODOLOGY}

\subsection{Material}

The copper slag sample used in the current study was donated by the Societe de Terril de Lubumbashi (STL). The slag was produced decades ago from a water-jacket furnace producing copper matte by Gecamines, in Lubumbashi, in the Democratic Republic of Congo. The FeSi and $\mathrm{Ca}_{2} \mathrm{SO}_{4}$ were provided by the Department of Metallurgy, University of Johannesburg. $\mathrm{Ca}_{2} \mathrm{SO}_{4}$ was used as sulfurizing agent and also to adjust the basicity to 1 since the slag was fayalitic.

\subsection{Experimental procedure}

The head samples were made of $4.5 \mathrm{~g}$ of carbon and $\mathrm{CaSO}_{4}$ to $0.7 \mathrm{~g}, \mathrm{FeSi}$ varied from 0.005 to $0.008 \mathrm{~g}$ with $0.001 \mathrm{~g}$ increment. $\mathrm{CO}$ was blown in the alumina tube furnace at a rate of $0.0011 / \mathrm{min}$. Graphite crucibles were used for the experiments. From room temperature to $600{ }^{\circ} \mathrm{C}$ argon was blown in the furnace then switched to $\mathrm{CO}$ up to $1400^{\circ} \mathrm{C}$. The samples were kept at $1400{ }^{\circ} \mathrm{C}$ for two hours and the furnace was switched-off to cool down while $\mathrm{CO}$ was still blown in until the furnace reached $600{ }^{\circ} \mathrm{C}$ then $\mathrm{CO}$ was switched-off and argon switched-on until room temperature was reached. The cold sample was collected and characterized. XRF, XRD and SEM were used for characterization.

\section{RESULTS AND DISCUSSION}

\subsection{XRF of the raw slag}

Iron oxides and silicon dioxide are the most abundant components indicating the presence fayalite containing copper, zinc and cobalt. This also make the copper slag amorphous and acidic.

Table 1 Chemical composition of raw slag [17]

\begin{tabular}{|c|c|c|c|c|c|c|c|c|}
\hline Comp. & $\mathrm{Fe}$ & $\mathrm{Cu}$ & $\mathrm{Co}$ & $\mathrm{Zn}$ & $\mathrm{SiO}_{2}$ & $\mathrm{CaO}$ & $\mathrm{Al}_{2} \mathrm{O}_{3}$ & $\mathrm{MgO}$ \\
\hline $\mathrm{wt} \%$ & 38.3 & 4.60 & 1.44 & 2.99 & 30.4 & 17.7 & 6.12 & 4.77 \\
\hline
\end{tabular}

\subsection{XRD of the raw slag}

The XRD analyses of the raw sample slag is presented in Figure 3. Orign 8.5 software was used to identify overlapping peaks.XRD pattern has revealed no peaks indicating a dominance of amorphous $\mathrm{SiO}_{2}$ as revealed by the XRF forming fayalite phase. The slag composition comprised cobalt oxide, copper aluminate spinel, jacobsite, magnesioferrite, magnetite, pyrite and zincite.

Based on the list of phases depicted from Figure 3 it transpired that either the oxygen potential was considerably high, or the amount of silica added did not fully assist in avoiding the formation of magnetite. Although the addition of silica did not stop the formation of some magnetite, the presence of fayalite confirms that the addition of silica has however limited the formation of magnetite at this stage. The presence of jacobsite in the slag, spinel phases also enjoy the explanation of the limitation of the formation of magnetite. This confirms the dissolution of other elements in the $\mathrm{Fe}_{2} \mathrm{O}_{3}$ matrix. It should, however, be noted that the oxidized iron should be low compared to iron that reported to the matte. Further, the presence of pyrite is and indication that some mattes were entrained or trapped in the slag when the slag was tapped while zincite confirms the presence of zinc sulfides in the ore that was used and most probably got oxidized during sintering of chalcopyrite prior the reverberatory furnace. Cobalt oxide has presumably entered the reverberatory furnace as oxide and did not take part in any reaction during copper matte production and reported to the slag. 



Figure 3 Phases present in the raw slag

\subsection{SEM-EDS of raw slag}

Figure 4 presents results obtained using SEM-EDS as analytical technique. Results show atom percentage of different element that are the sample. Four points were analyzed based on the color and morphology of the particles.

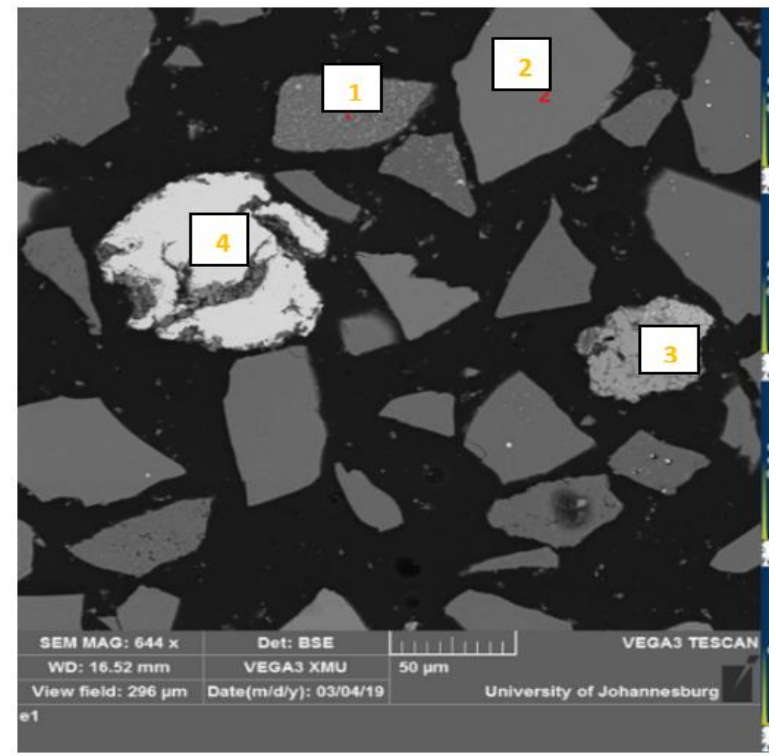

\begin{tabular}{|l|l|l|l|l|}
\hline $\begin{array}{l}\text { Element } \\
\text { at } \%\end{array}$ & 1 & 2 & 3 & 4 \\
\hline $\mathrm{O}$ & 47.3 & 48.6 & 55.1 & 1.2 \\
\hline $\mathrm{Mg}$ & 3.0 & 3.1 & 2.4 & 0 \\
\hline $\mathrm{Al}$ & 2.5 & 3.5 & 2.2 & 0 \\
\hline $\mathrm{Si}$ & 14.6 & 16.7 & 9.6 & 0 \\
\hline $\mathrm{P}$ & 0.3 & 0 & 0 & 0 \\
\hline $\mathrm{S}$ & 0.2 & 0 & 0 & 0 \\
\hline $\mathrm{K}$ & 0.3 & 0.6 & 1.7 & 0 \\
\hline $\mathrm{Ca}$ & 7.5 & 6.2 & 2.0 & 0 \\
\hline $\mathrm{Ti}$ & 0.2 & 0.3 & 0.3 & 0 \\
\hline $\mathrm{Fe}$ & 19.7 & 14.9 & 0 & 0.5 \\
\hline $\mathrm{Co}$ & 1.7 & 1.8 & 0 & 0 \\
\hline $\mathrm{Cu}$ & 0.7 & 0.6 & 7.0 & 98.2 \\
\hline $\mathrm{Zn}$ & 1.9 & 3.5 & 14.2 & 0 \\
\hline $\mathrm{As}$ & 0 & 0 & 1.3 & 0 \\
\hline $\mathrm{Pb}$ & 0 & 0 & 4.2 & 0 \\
\hline
\end{tabular}

Figure 4 SEM-EDS of raw slag 
The spectra revealed the complexity of the chemical composition of the raw slag as the head sample. It is observed that silicon and iron are the most abundant elements in the sample in oxide form. This informs the presence of abundant silica in the slag. This confirms and is in line with results obtained with XRD. The XRD spectra have shown that the sample was amorphous due to the presence of silica. The amount of iron in the sample is an indication that iron is either present as fayalite, magnetite, spinel phases, pyrite or magnesioferrite. Very little iron sulfide is oxidized and slagged: the furnace slag consists mainly of the cleaned (settling of matte droplets) converter slag, which is returned molten to the furnace. It is a confirmation of the results obtained through XRD. The explanation of the formation of the above-mentioned phases remained the same as supported by XRD spectra. The presence of aluminum is a confirmation of aluminate spinel depicted with XRD while copper, calcium, zinc and cobalt are present as oxides.

\subsection{XRD of smelted samples}

Figure 5 depicts phases formed at $0.005 \mathrm{~g}$ and $0.006 \mathrm{~g} \mathrm{FeSi}$. The spectra presented show the influence of $\mathrm{FeSi}$ and $\mathrm{CaSO}_{4}$ in a reducing atmosphere at $1400{ }^{\circ} \mathrm{C}$.


Figure $5 \mathrm{XRD}$ results of the matte produced with $0.005 \mathrm{~g}$ and $0.006 \mathrm{~g}$ of FeSi addition

It is found that different sulfide phases containing $\mathrm{Fe}, \mathrm{Cu}$ and Ge have formed. From the thermodynamic study conducted in Figure 1 it was predicted that at $1400{ }^{\circ} \mathrm{C}$, the formation of germanium sulfide was possible in a reducing atmosphere. The presence of germanium sulfide in the smelted samples enjoys the thermodynamic predictions. However, an increase in FeSi has led to freeing Ge. This can be due to the displacement of $\mathrm{Ge}$ by Si from the silicate matrix. The explanation is found in the fact that $\mathrm{Ge}$ and $\mathrm{Si}$ are of same atomic size with $\mathrm{Ge}$ being siderophile. $\mathrm{Ge}$ is therefore attracted by iron while $\mathrm{Si}$ has more affinity to oxygen than $\mathrm{Ge}$ and replaces $\mathrm{Ge}$ in the silicate matrix. Also, the presence of $\mathrm{Ge}$ in the metal signifies that $\mathrm{pSO}_{2}$ was very low as predicted with HSC 9 in Figure 2. However, the presence CuFeS, CoFeS preferentially got sulfurized while FeS might either be from the head sample or got sulfurized. The reported CoFe is a result of carbothermic reduction of their respective oxides from the head samples. The increase of FeSi has decreased CuS, FeGeS and favored the formation of CuFeS.

Figure 6 depicts phases formed at $0.007 \mathrm{~g}$ and $0.008 \mathrm{~g} \mathrm{FeSi}$ added. These results are compared to the results obtained with $0.005 \mathrm{~g}$ and $0.006 \mathrm{~g}$ FeSi addition. 

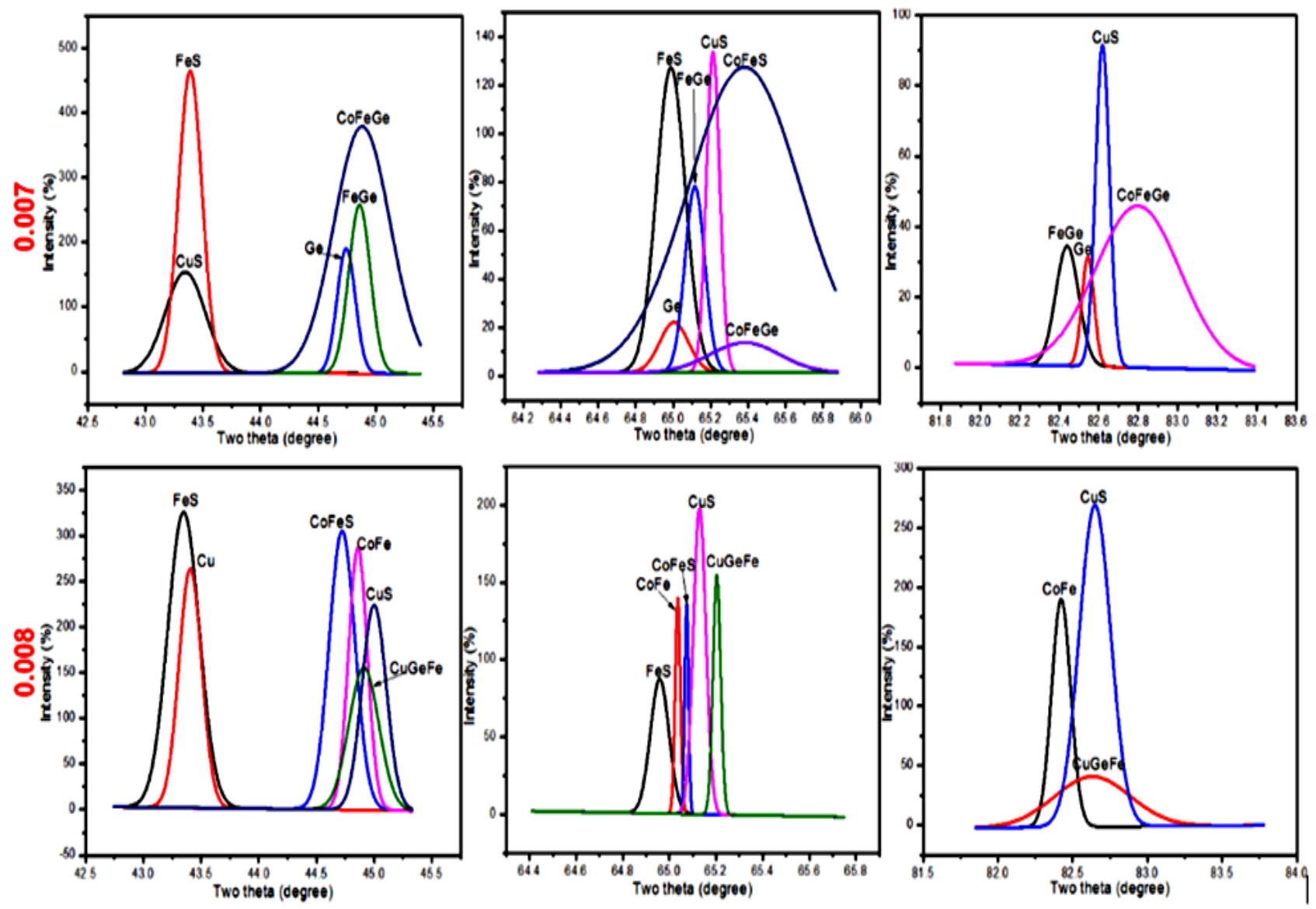

Figure 6 XRD results of the matte produced with $0.007 \mathrm{~g}$ and $0.008 \mathrm{~g}$ of FeSi addition

From Figure 6 it transpired that phases that formed are similar to those obtained with 0.005 and $0.006 \mathrm{~g} \mathrm{FeSi}$. However, a few displacements were observed. For germanium, further increase of FeSi showed that during smelting Ge, CoFeGe and FeGe became unstable and CuGeFe was favored. This could be due to the chalcophilic behavior of cupper being higher than that of cobalt. However, contrary to what was observed at lower FeSi addition in Figure 5, further increase of FeSi stabilizes CuS while CoFe becomes more stable due to high Fe content. The so-called trio FeCoNi supports the behavior similarity of the three elements. The formation of $\mathrm{CoFeS}$ enjoys the $\mathrm{FeCoNi}$ statement in presence of $\mathrm{CaSO}_{4}$. It was however expected to form more sulfides phases, but that was not the case. This could be due to short residence time of $\mathrm{SO}_{2}$ in the furnace. After the decomposition of $\mathrm{CaSO}_{4}, \mathrm{SO}_{2}$ easily escapes from the furnace, hence less contact time with the head sample. This leads to less contact time between the gas and the solid particles.

\section{CONCLUSION}

Experiments conducted in this study aimed to explore the influence of ferro-silicon addition on the carbothermic reduction of Ge-Copper bearing slag. XRF, XRD and SEM-EDS used to characterize the raw slag which has shown no germanium trace and a fayalitic copper slag. Thermodynamic predictions using HSC 9 software were in line with the results obtained. Results have revealed that under reducing conditions at low $p\left(\mathrm{SO}_{2}\right) \mathrm{Ge}$ was stabilized but became unstable when FeSi increased. Further increase of $\mathrm{FeSi}$ to $0.0008 \mathrm{~g}$; $\mathrm{Ge}$, CoFeGe and $\mathrm{FeGe}$ became unstable and $\mathrm{CuGeFe}$ was favored. Also, it was found that $\mathrm{FeSi}$ stabilized $\mathrm{CuS}$ and $\mathrm{CoFe}$ while less sulfide phases were attributed to short residence time of $\mathrm{SO}_{2}$ in the furnace. The overall observation has shown that the use $\mathrm{FeSi}$ in addition to $\mathrm{CaSO}_{4}$ in reducing conditions it is possible to recover base metals in an alloyed form. 


\section{ACKNOWLEDGEMENTS}

\section{The authors express their special gratitude to Mr Grant Dempsey, General Manager of STL for having made the current study a new path in the recovery of metals from copper slag and Gecamines for the interaction.}

\section{REFERENCES}

[1] GUO, Z., ZHU, D., PAN, J., WU, T., ZHANG, F. Improving beneficiation of copper and iron from copper slag by modifying the molten copper slag. Metals. [online]. 2016, vol. 6, no. 4, p. 86. Available from: https://doi.org/10.3390/met6040086.

[2] DHIR, R. K. et al. Production and properties of copper slag, sustainable construction materials. Copper Slag. 2016, pp. 27-86.

[3] LI, Y., CHEN, Y., TANG, C., YANG, S., HE, J., TANG, M. Co-treatment of waste smelting slags and gypsum wastes via reductive-sulfurizing smelting for valuable metals recovery. Journal of Hazardous Materials. 2017, vol. 322, pp. 402-412.

[4] KAYEMBE, J., KALENGA, M., NYEMBWE, D. Effect of basicity and ferro-silicon addition matte formation from Ge-copper bearing slag. MS\&T18. 2018, no. 1, pp. 1125-1131.

[5] LAN, X., GAO, J., HUANG, Z., GUO, Z. Rapid separation of copper phase and iron-rich phase from copper slag at low temperature in a super-gravity field. Metallurgical and Materials Transactions B. [online]. 2018, vol. 49, no. 3, pp. 1165-1173. Available from: https://doi.org/10.1007/s11663-018-1235-6.

[6] BELLEMANS, I., DE WILDE, E., MOELANS, N., VERBEKEN, K. Metal losses in pyrometallurgical operations - A review. Advances in Colloid and Interface Science. Elsevier B.V., 2018, pp. 47-63.

[7] FONT, O., MORENO, N., AIXA, G.X., QUEROL, R. N. Copper smelting flue dust: A potential source of germanium. Macla, revista de la sociedad española de mineralogía. 2011, vol. 15, pp. 87-88.

[8] SÁNCHEZ, M., SUDBURY, M. Physicochemical characterization of copper slag and alternatives of friendly environmental management. Journal of Mining and Metallurgy, Section B: Metallurgy. 2013, vol. 49, no. 2, pp. 161-168.

[9] WANG, X. et al. Characterization of copper slag in view of metal recovery. Mineral Processing and Extractive Metallurgy. 2015, vol. 124, no. 2, pp. 83-87.

[10] TORRALVO, F. A., FERNÁNDEZ-PEREIRA, C. Recovery of germanium from real fly ash leachates by ionexchange extraction. Minerals Engineering. Elsevier Ltd. 2011, vol. 24, no. 1, pp. 35-41.

[11] MOSKALYK, R. R. Review of germanium processing worldwide. Minerals Engineering. 2004, vol. 17, no. 3, pp. 393-402.

[12] ARROYO, F., FERNANDEZ-PEREIRA, C., COCA, P. Precipitation of germanium from coal fly ash leachates. Coal Combustion and Gasification Products. 2010, vol. 2, no. 1, pp. 28-34.

[13] FRENZEL, M., KETRIS, M. P., GUTZMER, J. On the geological availability of germanium. Mineralium Deposita. 2014, vol. 49, no. 4, pp. 471-486.

[14] NUSEN, S. et al. Recovery of germanium from synthetic leach solution of zinc refinery residues by synergistic solvent extraction using LIX 63 and lonquest 801. Hydrometallurgy. Elsevier B.V., 2015, vol. 151, pp. 122-132.

[15] SONG, Q., ZHANG, L., XU, Z. Kinetic analysis on carbothermic reduction of $\mathrm{GeO}_{2}$ for germanium recovery from waste scraps. Journal of Cleaner Production. Elsevier Ltd, 2019, vol. 207, pp. 522-530.

[16] BARTON, L., HEIL, C. A. The reduction of germanium dioxide with graphite at high temperatures. Journal of the Less-Common Metals. 1970, vol. 22, no. 1, pp. 11-17.

[17] KAYEMBE, J., KALENGA, M., NYEMBWE, D. Impact of Ferro-Silicon and gypsum on the recovery of copper from copper slag. METAL 2019, 28 $8^{\text {th }}$ International Conference on Metallurgy and Materials Proceedings, pp. 17381746 . 